\title{
Analyzing key factors of roots and soil contributing to tree anchorage of Pinus species
}

\author{
Ming Yang ${ }^{1} \cdot$ Pauline Défossez $^{1} \mathbb{1} \cdot$ Frédéric Danjon $^{2} \cdot$ Thierry Fourcaud $^{3}$
}

Received: 2 May 2017 / Accepted: 19 January 2018

(c) Springer-Verlag GmbH Germany, part of Springer Nature 2018

\begin{abstract}
Key message Root anchorage strength and stiffness can be represented by small number of root and soil parameters. Root morphology represents the majority of these factors.

Abstract Tree anchorage is a primary function for plant survival which may reach its limit under extreme conditions such as windstorms. To better understand the processes and influential factors underlying tree anchorage, we analyzed the mechanical effects of root morphology and the material properties of roots and soil on the tree-overturning process with the recently developed finite element model RootAnchor. The root system was represented by a simplified 3D root pattern derived from an ensemble average of seven measured root systems of 19-year-old Pinus pinaster grown in sandy spodosol. Soil properties were measured by direct shear tests. Taguchi orthogonal arrays were used to examine the sensitivity of the geometric and material factors of roots and soil to tree anchorage. Tree anchorage was characterized by anchorage strength TMc and anchorage stiffness K0. Using a small number of numerical experiments, the sensitivity analysis prioritized only two key factors contributing to tree anchorage among the 34 factors considered. The results showed root morphological traits that played a dominant role in the material properties of roots and soil in tree anchorage. Taproot depth, the dimensions of the Zone of Rapid Taper (ZRT) and basal diameter of the windward shallow roots were the key factors contributing to TMc (variations $>8 \%$ ). The dimensions of the taproot, root and soil stiffness, and the basal diameter of the leeward shallow roots were the most active factors for K0 (variations $>10 \%$ ). These results provide insight into simplified tree anchorage expressions for the prediction of wind-induced uprooting.
\end{abstract}

Keywords Tree anchorage $\cdot$ Sensitivity analysis $\cdot$ Taguchi orthogonal arrays $\cdot$ Finite element method $\cdot$ Pinus pinaster $\cdot$ Root architecture

\section{Introduction}

Windstorms are a major hazard that causes damage in European forests. The risk of wind-induced damage could increase further due to the increasing stock of European forests and predicted higher windstorm intensity in the future

Communicated by K. Noguchi.

Pauline Défossez

pauline.defossez@inra.fr

1 ISPA, INRA, Bordeaux Sciences Agro, 33140 Villenave d'Ornon, France

2 BIOGECO, INRA, Université de Bordeaux, 33610 Cestas, France

3 AMAP, CIRAD, CNRS, INRA, IRD, Université de Montpellier, 34398 Montpellier Cedex 5, France
(Gardiner et al. 2010). Many attempts have been made to model wind and tree interactions at different scales ranging from individual trees to entire forests (Gardiner et al. 2000; Hale et al. 2015; Sellier et al. 2008; Rodriguez et al. 2008; Pivato et al. 2014; Dupont et al. 2015a, b; Dupont 2016). These models provide good understanding of interactions between tree aerial parts and winds, but the prediction of tree anchorage failure remains absent or empirical. Knowledge on tree anchorage has progressed with detailed analyses of root architecture, tree-pulling experiments and numerical simulations (Coutts 1983; Stokes 1999; Ennos 2000; Dupuy et al. 2005; Danjon et al. 2005; Fourcaud et al. 2008; Achim and Nicoll 2009; Yang et al. 2017). Although findings have evidenced several important factors involved in tree anchorage, a good estimation requires a synthetic overview based on the full evaluation of all the factors involved. Therefore, it is important to characterize and quantify the relative effects 
of roots and soil properties on tree anchorage. In this study, we attempt to provide a concise analysis of the geometry and material factors of roots and soil impacting tree anchorage for a given species and soil environment.

Tree anchorage is characterized by the stiffness of the root-soil system against the bending of aerial parts and ultimate anchorage strength when the tree is uprooted. Treepulling experiments provide good understanding of tree anchorage. Aspects of root and soil deformations and failure during tree overturning can be observed and recorded, and the response of the root-soil system can be expressed by the turning moment response curve as a function of the rotation angle measured at the stem base (Nicoll et al. 2006). In our study, we define $\mathrm{K} 0$ as the initial slope of the curve of turning moment versus the rotation angle; and TMc the maximum turning moment during tree overturning.

$\mathrm{K} 0$ and TMc are indicators of anchorage performance of trees throughout different developmental stages. Trees of lower $\mathrm{K} 0$ rotate much more under the same wind loading. As the roots and stump of young trees are less stiff and more plastic, this rotation does not necessarily lead to rupture but could become permanent afterwards (e.g., inducing toppling corresponding to permanent stem leaning of more than $15^{\circ}$ ). Although the trees survive and continue to grow with stem leaning or toppling, this flaw in the juvenile phase leads to a serious risk of uprooting during high wind events when the trees grow older and to problems of wood quality (Moore et al. 2008; Danquechin Dorval et al. 2016). K0 has been investigated using non-destructive tree-pulling experiments and numerical models of tree anchorage (Fraser and Gardiner 1967; Neild and Wood 1999; Jonsson et al. 2006; James et al. 2013). Measured strain distribution during loading and root architecture suggest the main structural roots are important factors impacting anchorage stiffness (Coutts et al. 1999; Stokes 1999; Danquechin Dorval et al. 2016). For shallowly rooted Picea sitchensis, asymmetric shallow roots due to root losses are believed to significantly reduce anchorage stiffness (Coutts et al. 1999). However, root acclimation due to wind is likely to improve anchorage stiffness in a given direction (Nicoll and Ray 1996). For young Pinus pinaster, a large taproot and deep roots may secure anchorage and thicker leeward shallow roots could enhance anchorage stiffness (Danjon et al. 2005). Planted trees present higher flexural stiffness in windward shallow roots to compensate for lower taproot stiffness (Danquechin Dorval et al. 2016). Numerical tree-pulling experiments show that root elastic modulus is also an important factor of K0 (Yang et al. 2014). For adult trees, the common type of anchorage failure is uprooting, characterized by TMc. Tree-uprooting results from a combination of successive root damage, soil failure and root-soil mechanical interactions. To understand these underlying mechanisms, field and numerical tree-pulling experiments were carried out. Deformations and the possible failure of roots and surrounding soil were recorded to identify local responses of the root-soil system (Coutts 1983, 1986; Stokes 1999; Dupuy et al. 2005, 2007; Fourcaud et al. 2008; Ghani et al. 2009; Yang et al. 2017). This approach identifies the windward and leeward roots, the weight of the root-soil plate and soil strength as the main components of anchorage. Numerical tree-pulling experiments suggest that heart-like root systems provide greater anchorage strength among four common types of root system architectures (RSA) in various soil types (Dupuy et al. 2005). For tap root systems, the taproot is found to contribute significantly to anchorage strength (Crook et al. 1997). In particular, numerical tree-pulling experiments have shown that a large taproot is the predominant factor contributing to $\mathrm{TMc}$, and that windward shallow roots are most stressed in tension when anchorage failure occurs in sandy soils (Dupuy et al. 2005; Fourcaud et al. 2008; Yang et al. 2017).

These previous studies pointed out important factors of tree anchorage but a quantitative synthetic overview remains missing. This is not easy to achieve with experimental studies because observations are dependent on the tree specimens and site conditions tested. The substantial variability of tree root systems and soil conditions would require very extensive sampling to generalize the experimental findings. Furthermore, experimental approaches also make it difficult to dissociate the contributions of the different factors (root dimensions, root distribution, soil, etc.) to tree anchorage. Numerical tree-pulling experiments can be performed to examine the different factors separately and may consider large datasets expressing the variability of root systems and soils. However, previous numerical studies on tree anchorage investigated the tree anchorage either from the theoretical aspect (Dupuy et al. 2005; Fourcaud et al. 2008) or focused on exploring only one specimen (Dupuy et al. 2007; Yang et al. 2017). In addition, root and soil factors were investigated separately for $\mathrm{K} 0$ and $\mathrm{TMc}$, often using different tree specimens under contrasting site conditions. Therefore, to obtain better understanding of tree anchorage and the key factors involved, it is necessary to: (1) propose a concise and generic method to analyze the relationship between tree anchorage ( $\mathrm{K} 0$ and $\mathrm{TMc}$ ) and the geometric and material factors involved; (2) identify the key geometric and material factors acting on $\mathrm{K} 0$ and $\mathrm{TMc}$ by their relative effects.

Considering both $\mathrm{K} 0$ and $\mathrm{TMc}$ should lead to identifying the factors relevant to root system stiffness and the stability of young specimens, and the factors relevant to root system strength and the stability of mature specimens.

The aim of the present study was to identify the main morphological and material traits of roots and soil that impact tree anchorage stiffness and anchorage strength. Previous studies on the aerial parts of trees showed that tree morphological traits predominate regarding the effects of material properties on tree dynamic behavior (Sellier et al. 
2008; Sellier and Fourcaud 2009). We hypothesized that this holds true for the behavior of tree below-ground parts, and that only a small number of root morphology traits play a significant role in the tree overturning process. $P$. pinaster was chosen as the model species as it is vulnerable to winter storms in Europe. We used a biomechanical RootAnchor model to perform numerical tree-pulling experiments. The model was validated previously, first by a field tree-pulling experiment with a measured root system architecture and root and soil material properties. Then, the simplification of the root system architecture and the tree anchorage resulting from it were validated by comparison with 24 measured root systems and empirical relationships from 100 tree-pulling experiments (Cucchi et al. 2004; Yang et al. 2014, 2017). In the current study, we assume the validated model should provide a reliable physical interpretation of tree anchorage. Numerical experiments were performed using Taguchi orthogonal arrays to prioritize the most influential factors of roots and soil on tree anchorage. The results attempt to provide more synoptic understanding of tree stability to wind and recommend future studies to focus efforts on the essential part of the problem.

\section{Materials and methods}

\section{Anchorage model}

The finite element model of root anchorage was developed to simulate the tree overturning process (Abaqus; http:// www.3ds.com/products-services/simulia/portfolio/abaqus/ latest-release/). The model was first tested using a digitized young specimen of $P$. pinaster against the corresponding tree-pulling experiment, yielding satisfactory results (Yang et al. 2014). Then a modified version of the model, RootAnchor, was developed by introducing 3D root patterns representing real root systems of adult Pinus species (Yang et al. 2017). This version was validated by an empirical estimation of anchorage. More details of model development and validation can be found in Yang et al. (2014, 2017). The RootAnchor model was used in our sensitivity analysis. This was the version of Yang et al. (2017). The model was composed of a large parallelepiped soil domain discretized with 8-node linear brick elements (length $\times$ width $\times$ depth: $10 \mathrm{~m} \times 10 \mathrm{~m} \times 5 \mathrm{~m}$ ), a root system discretized with 2-node linear beam elements and placed in the center of the soil domain, and a rigid vertical stem of negligible mass attached to the top of the root stump. Tree pulling was mimicked by a horizontal displacement of $1.2 \mathrm{~m}$ applied at a height of $1.6 \mathrm{~m}$ on the stem. The entire root-soil system was also constantly subjected to gravity load during the overturning process, with a vertical downward acceleration $g$ of $9.81 \mathrm{~m} / \mathrm{s}^{2}$. In terms of boundary conditions for the soil domain, the nodal displacements of the bottom of the soil domain were set to 0 . The outward and inward nodal displacements of each vertical face of the soil domain border were also set to 0 to prevent outward or inward deformations of these vertical planes with respect to the initial soil domain. As the soil domain was sufficiently large compared to the soil area occupied by the root system, these boundary conditions should have a negligible effect on the simulated tree-overturning behavior.

The root system was described by a virtual root pattern following the method given in Yang et al. (2017). This method consists in building a 3D virtual root pattern from a set of real root systems measured in detail. Figure 1-a depicts the typical root system architecture of $P$. pinaster summarized by the reference root pattern. The main architectural characteristics of this root pattern are representative of typical sinker root systems of several Pinus species found in Europe (Köstler et al. 1968). Yang et al. (2017) showed that the leeward chuck root, the second-order intermediate depth oblique root and the third-order sinker roots in the leeward and perpendicular sectors had little impact

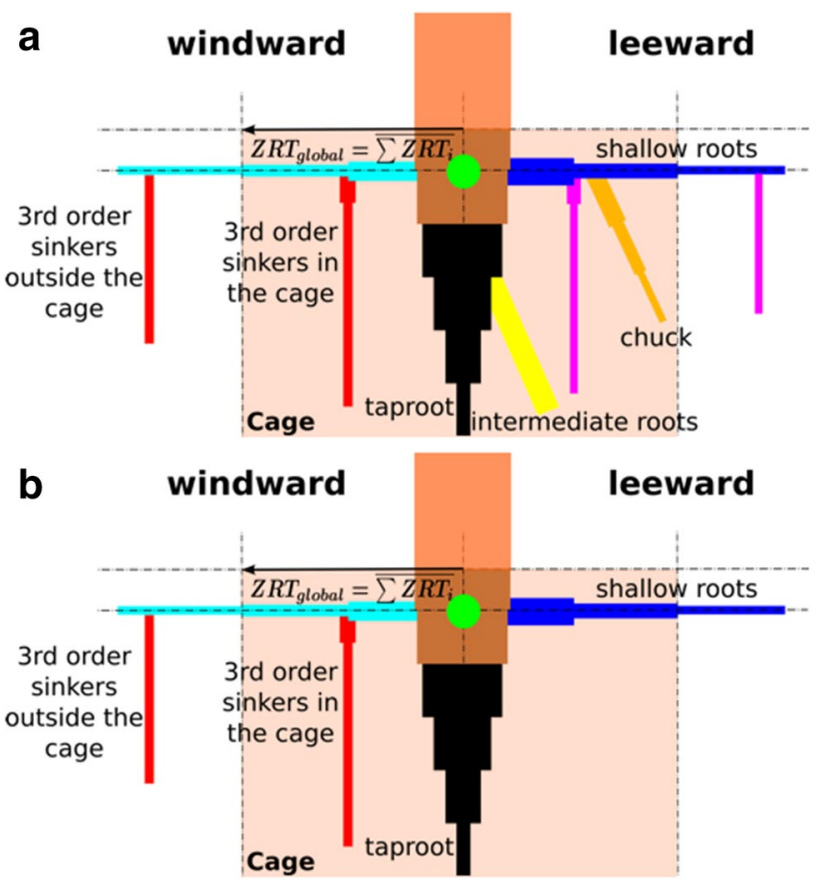

Fig. 1 Representation of a typical sinker root system of Pinus pinaster growing in sandy podzols. a Side view of typical sinker root system architecture of $P$. pinaster represented by a 3D visual root pattern. The root pattern is composed of a taproot, shallow roots, a second-order intermediate root, third-order sinker roots and a leeward chuck root. This pattern represents a typical root system of $P$. pinaster deduced from different datasets of measured root systems (Danjon et al. 2005, 2013). b Side view of the reference 3D root pattern used in our sensitivity analysis, only with major structural root components: taproot, shallow roots and windward third-order sinker roots. This simplification was deduced from numerical experiments (Yang et al. 2017) 
on tree anchorage. Therefore, these root components were excluded in our study. Thus, the modified root pattern used in our sensitivity analysis was composed only of the taproot, the shallow roots and the windward third-order sinker roots (Fig. 1b).

Constitutive laws for root wood material and soil material remain the same as those described in Yang et al. (2017). Soil material properties were assumed to be linearly elastic at the initial state and plastic following the Mohr-Coulomb failure criterion. Roots were assumed to be quasi-brittle materials characterized by linearly elastic behavior at the initial state and by damage behavior as a function of a damage criterion and a damage evolution law. Root segments were thus able to fail in tension, compression and bending. Root-soil interactions were modeled by the embedded element method which imposed the kinematic consistency of root nodal displacements and that of the soil nodes in the immediate vicinity.

Tree below-ground anchorage behavior was studied by examining the curve of the turning moment as a function of rotation angle at the stem base, the initial slope of the curve characterizing the anchorage stiffness $\mathrm{K} 0$ and the maximum turning moment characterizing the anchorage strength TMc.

\section{Input factors for sensitivity analysis}

The model input factors for sensitivity analysis were those of Yang et al. (2017). They contained the set of root morphology parameters and the set of root and soil material property parameters summarized in Tables 1 and 2, respectively.

The root pattern was composed of a large taproot maintained by horizontal shallow roots in all directions. thirdorder sinker roots were only present in the windward sector. Root taper was interpreted only for the taproot and the zone of rapid taper (ZRT) by a chain of root segments with tapering diameters (Fig. 1b). The reference values of the root geometric parameters in Table 2 were determined from the ensemble average of seven measured root systems of adult P. pinaster (dataset L19 in Danjon et al. 2013a). 19-yearold trees with a mean diameter at breast height (DBH) of $28.45 \mathrm{~cm}$ were excavated from site $\mathrm{L}$. The site was located in southwest France $\left(44^{\circ} 42^{\prime} \mathrm{N}, 0^{\circ} 46^{\prime} \mathrm{W}\right)$ with a mean annual rainfall of $850 \mathrm{~mm}$ and a mean annual temperature of $13{ }^{\circ} \mathrm{C}$. The site was characterized by a sandy podzol with a deep discontinuous hard pan located at about $100 \mathrm{~cm}$ depth and a water table close to the soil surface during winter. Further information on root system measurements and site conditions can be found in Danjon et al. (2013). The method used for root pattern parametrization with respect to adult $P$. pinaster features and its validation can be found in Yang et al. (2017).

For the sake of simplicity, all the reference root material parameters were held constant within the root pattern. Root material was characterized by its density, elastic modulus, the ratio of shear modulus to elastic modulus, tensile strength, compressive strength and fracture energy. The reference values of root material parameters were derived from green wood data in the literature, as described in Yang et al. (2014).

Soil material was characterized by its density, elastic modulus, Poisson's ratio, soil cohesion and internal friction angle. The reference values of these parameters were determined by direct shear tests in the laboratory. Samples were collected in the Nézer forest in southwest France $\left(44^{\circ} 36^{\prime} \mathrm{N}\right.$, $\left.1^{\circ} 1^{\prime} \mathrm{W}\right)$. The site is a medium humid sandy podzol with a discontinuous deep hard pan at 40-90 cm depth, similar to site L19 (Augusto et al. 2015). Soil was sampled at 12 locations and at three depths. The bulk density and water content measured from these soil samples were used to reconstitute the sandy soil samples used for direct shear tests. More information on soil sampling and mechanical tests can be found in Yang et al. (2014).

\section{Numerical experiments}

To discriminate the key factors influencing tree stability, sensitivity analyses were performed separately on the two parameter sets described in Tables 1 and 2. Taguchi orthogonal arrays were used to design the numerical experiments, in the same way as Sellier and Fourcaud (2009) who investigated the separate influences of the geometric and material properties of the tree's aerial parts on its aerodynamic behavior. We applied Taguchi orthogonal arrays and the analysis of marginal means in the Taguchi method for our sensitivity
Table 1 Parameters of roots and soil materials described in Yang et al. (2017): elastic and plastic behavior (Mohr-Coulomb) for soil and elastic-brittle behavior for roots

\begin{tabular}{llllll}
\hline Items (soil) & Value & Units & Items (roots) & Value & Units \\
\hline Density & 1410 & $\mathrm{~kg} / \mathrm{m}^{3}$ & Density & 421.4 & $\mathrm{~kg} / \mathrm{m}^{3}$ \\
Elastic modulus & 19.86 & $\mathrm{MPa}$ & Elastic modulus & 8 & $\mathrm{GPa}$ \\
Poisson's ratio & 0.33 & - & Shear modulus/elastic modulus & 0.08 & - \\
Cohesion & 21.4 & $\mathrm{KPa}$ & Tensile strength & 43.2 & $\mathrm{MPa}$ \\
Friction angle & 14.62 & & Compressive strength & 20.6 & $\mathrm{MPa}$ \\
& & & Energy of fracture & 209.4 & $\mathrm{~J} / \mathrm{m}^{2}$ \\
\hline
\end{tabular}

In total, there are 11 material factors for the root-soil system 
Table 2 Main architectural characteristics of the reference root pattern in sensitivity analysis based on the seven measured root systems of L19 dataset described in Yang et al. (2017)

Root morphological parameters

Reference values based on L19 root systems (unit in $\mathrm{cm}$ for root geometric parameters)

$\begin{array}{lc}\text { ZRT radial dimension } & 87.03 \\ \text { Taproot basal diameter } & 29.22 \\ \text { Taproot intermediate diameter 1 } & 21.06 \\ \text { Taproot intermediate diameter 2 } & 12.94 \\ \text { Distal diameter of the taproot } & 5.11 \\ \text { Taproot depth } & -112.78 \\ \text { Windward shallow root number } & 5 \\ \text { Basal diameter of windward shallow roots } & 4.82 \\ \text { Diameter at the end of ZRT of windward shallow roots } & 3.72 \\ \text { Diameter beyond the ZRT of windward shallow roots } & 2.2 \\ \text { Windward shallow root length beyond the ZRT } & 157.25 \\ \text { Perpendicular shallow roots number } & 10 \\ \text { Basal diameter of perpendicular shallow roots } & 5.91 \\ \text { Diameter at the end of ZRT of perpendicular shallow roots } & 4.25 \\ \text { Diameter beyond the ZRT of perpendicular shallow roots } & 2.26 \\ \text { Perpendicular shallow root length beyond the ZRT } & 124.48 \\ \text { Leeward shallow roots number } & 5 \\ \text { Basal diameter of leeward shallow roots } & 5.44 \\ \text { Diameter at the end of ZRT of leeward shallow roots } & 4.02 \\ \text { Diameter beyond the ZRT of leeward shallow roots } & 2.27 \\ \text { Leeward shallow root length beyond the ZRT } & 153.65 \\ \text { Basal diameter of the leeward shallow root carrying the chuck } & 10.74 \\ \text { Number of windward sinker roots in the ZRT } & 5 \\ \text { Basal diameter of windward sinker roots in the ZRT } & 4.16 \\ \text { Distal diameter of windward sinker roots in the ZRT } & 2.34 \\ \text { Length of windward sinker roots in the ZRT } & 84.86 \\ \text { Number of windward sinker roots beyond the ZRT } & 5 \\ \text { diameter of windward sinker roots beyond the ZRT } & 1.71 \\ \text { Length of windward sinker roots beyond the ZRT } & 62.01\end{array}$

Note that among these factors, the number of root components holds constant in sensitivity analysis; and the basal diameter of the leeward shallow root carrying the chuck varies the same way as the basal diameter of other leeward shallow roots. Therefore, in total, there are 23 geometric factors. We defined 0 for the soil surface level, then negative for any root depth

analysis. This part of the Taguchi method allows qualitative factor screening when considering a large number of input factors. The fractional factorial design of the orthogonal arrays is efficient for time-consuming models because the number of experiments can be significantly reduced. Other concepts proposed by Taguchi for optimization purposes were not applied as they were not relevant to the objective of this study. Despite the fact that the Taguchi method was originally developed to optimize industrial parameters, it has been applied in various research fields (Dar et al. 2002; Autrique and Lormel 2008; Lin et al. 2010; Shabani and Kumar 2014). Using orthogonal arrays, allows reducing the number of experiments to an acceptable level without restricting the scope of the problem (Taguchi 1987). In our case, we tested 23 root geometric factors (Table 2) and 11 factors for both roots and material properties (Table 1). The variation of all the input factors was systematically characterized by three levels: the reference level defined in Tables 1 and 2, and the variations of -20 and $+20 \%$ with respect to the reference level. We applied the standard orthogonal arrays L54 $\left(2^{1}, 3^{25}\right)$ and L27 $\left(3^{13}\right)$ of the Taguchi method to the geometric parameter set and material parameter set, respectively. L54 $\left(2^{1}, 3^{25}\right)$ is the orthogonal array used to test a maximum number of 25 factors with three-level variation and one factor with twolevel variation. $\mathrm{L} 27\left(3^{13}\right)$ is the orthogonal array used to test a maximum number of 13 factors all with three-level variations. In our case, only 23 columns of L54 $\left(2^{1}, 3^{25}\right)$ were used for 23 geometric factors with three-level variations, and 11 columns of $\operatorname{L27}\left(3^{13}\right)$ for 11 material factors. The orthogonal arrays reduced the number of experiments from $3^{23}$ to 
54 for the geometric parameter set, and from $3^{11}$ to 27 for the material parameter set (see Yang, 2014 for details about Taguchi orthogonal arrays L54 $\left(2^{1}, 3^{25}\right)$ and L27 $\left.\left(3^{13}\right)\right)$. The sensitivity of the system response $Y$ to the variation of any given input variable $i$ was defined by the relative variation of $Y$, i.e., initial anchorage stiffness $\mathrm{K} 0$ and critical turning moment TMc:

$$
\operatorname{Var}_{j}^{i}(Y)=\frac{\dot{\bar{Y}}_{j}^{i}}{\overline{\bar{Y}}}
$$

where $\operatorname{Var}_{j}^{i}$ was the relative variation of the output $Y(Y$ represents either the anchorage stiffness $\mathrm{K} 0$ or the critical turning moment TMc) estimated for input factor $i$ (from either the geometrical parameter set or the material parameter set) at variation $j(-20 \%, 1$ or $+20 \%$ with respect to the reference value in Table 1 or 2), $\bar{Y}$ the mean value of the output variable averaged over all the simulations performed for the geometric or material parameter set, and $\bar{Y}_{j}^{i}$ the mean

value of the output variable averaged over the simulations for which the variation of factor $i$ was $j$.

The output anchorage strength TMc was defined as the maximum turning moment during the tree overturning process and anchorage stiffness $\mathrm{K} 0$ was calculated with $\mathrm{TM} / \theta$ where TM is the turning moment and $\theta$ the rotation angle at the stem base. K0 was determined using the first two increments of loading in the simulation, representing the initial elastic part the response curve.

\section{Results}

\section{Impacts of root morphological traits on TMC and KO}

Figure 2 showed the effects of $\pm 20 \%$ variations of each geometric parameter on the critical turning moment TMc and the initial stiffness $\mathrm{K} 0$ of the root-soil system. TMc was insensitive to most of the root geometric parameters. 19 of the 23 tested parameters caused negligible TMc variations $(\leq 5 \%)$. Only three parameters describing the taproot depth and the dimensions of ZRT gave rise to the most noticeable TMc variations of $13-16 \%$, which did not reach the level of the input variations. In particular, we identified an almost linear positively correlated TMc variation of 13-14\% induced by $\mathrm{a} \pm 20 \%$ variation of taproot length. Sensitive $\mathrm{TMc}$ responses also occurred for the variation of $+20 \%$ in the intermediate diameter of the taproot (measured at threefourths of the total taproot length from the base) and the radial dimension of the ZRT. Furthermore, the basal diameter of the windward shallow roots exhibited a secondary influence on TMc, with a gain of $8.3 \%$ in TMc if the basal diameter thickened by $20 \%$. Unlike TMc, K0 varied more noticeably with root geometric variations. Only three parameters caused negligible effects on $\mathrm{K} 0$, with variations lower than 5\%. Nevertheless, 18 of the total 23 parameters caused
K0 variations smaller than the input variations of $\pm 20 \%$. Four parameters provided amplified effects on $\mathrm{K} 0$ with their variations. Most pronounced changes in $\mathrm{K} 0$ were driven by the factors characterizing the taproot. A taproot with a basal diameter thickened by $20 \%$ reinforced $\mathrm{K} 0$ by $36 \%$. A gain of $20 \%$ in taproot depth led to a gain of $49 \%$ in $\mathrm{K} 0$. The $20 \%$ increase of the taproot intermediate diameter (measured at mid-depth) led to a $37 \%$ increase of K0. Leeward shallow roots could reinforce K0 by $32 \%$ with a thickened basal diameter.

\section{Impacts of roots and soil materials on TMc and KO}

Figure 3 showed the variations of TMc and $\mathrm{K} 0$ in response to variations in the factors of root and soil material properties. As with the case of geometric variations, most of the material parameters had little effect on TMc. Nevertheless, a several root and soil material strength parameters played non-negligible but second ary roles in TMc. Variations in root tensile strength and root compressive strength produced positively correlated TMc variations of $5.2-8.2 \%$. The increased internal friction angle of the soil also caused a comparable $8 \%$ gain in TMc. Reduced soil cohesion caused a loss of TMc of $6.3 \%$. As with the case of the root geometric parameter dataset, $\mathrm{K} 0$ variations were more noticeable than those of TMc. The root elastic modulus had the most significant impact on K0. An increase of $20 \%$ in root elastic modulus led to an increase of $55.0 \%$ in $\mathrm{K} 0$, higher than the influence of the taproot geometric factors. Reduced root elastic modulus decreased $\mathrm{K} 0$ by $15.6 \%$. In addition, a lower soil elastic modulus led to a $20.7 \%$ reduction of K0. An increase in soil elastic modulus led to an increase of $12.0 \%$ of K0. Other results not discussed here either had unclear output tendency or presented output variations lower than $10 \%$.

\section{Discussion}

Tree anchorage strength TMc was found to be insensitive to most root geometric factors and to all of the material factors of the root-soil system. Only three root geometric factors were able to produce effects on TMc comparable to the input variations of $\pm 20 \%$ : taproot depth, ZRT radial dimension, and taproot intermediate diameter. These geometric factors constitute a volume equivalent to the dimensions of the root-soil plate. This scheme clearly reflects the strategy of using the root-soil plate to evaluate TMc in certain experimental and empirical modeling studies. For instance, Peltola et al. (1999) modeled TMc with the mass of the root-soil plate and rooting depth. Cucchi et al. (2004) showed that the TMc of $P$. pinaster was closely correlated to the radial dimensions of the root-soil plate and rooting depth. This 

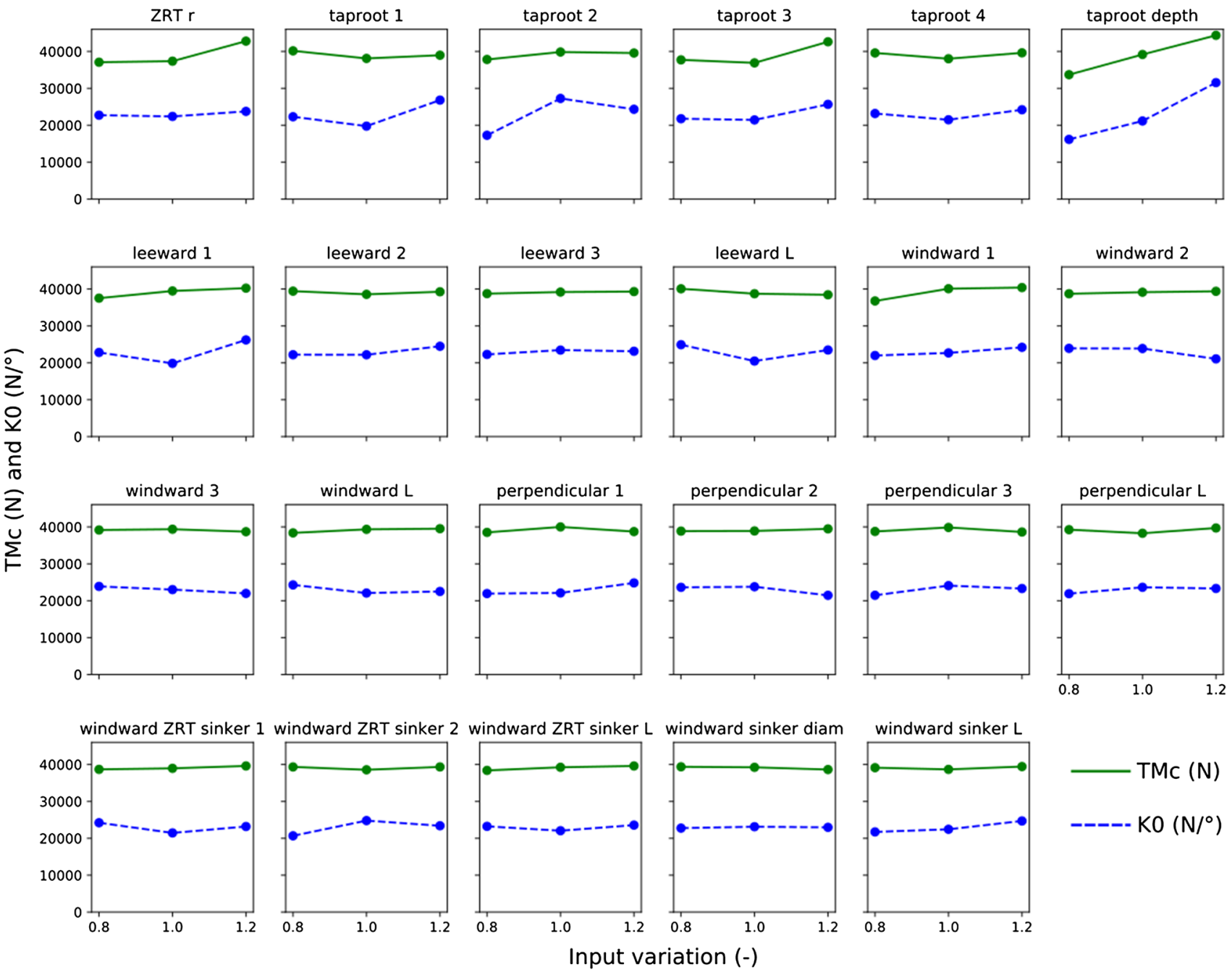

Fig. 2 Variation in anchorage strength TMc (unit in N.m; green solid lines) and anchorage rigidity (unit in $\mathrm{N} . \mathrm{m} /{ }^{\circ}$; blue dashed lines) in response to $\pm 20 \%$ variations in root geometric parameters. The 23 root geometric parameters shown in the figure are: $Z R T r$ radius of the ZRT, taproot 1 taproot base diameter, taproot 2 taproot intermediate diameter, taproot 3 taproot intermediate diameter, taproot 4 taproot distal diameter, taproot depth taproot depth measured from the soil surface, leeward 1 base diameter of the leeward shallow roots, leeward 2 intermediate diameter of the leeward shallow roots, leeward 3 distal diameter of the leeward shallow roots, leeward $L$ length of the leeward shallow roots outside the ZRT, windward 1 base diameter of the windward shallow roots, windward 2 intermediate diameter of the windward shallow roots, windward 3 distal diameter of the wind-

result is also relevant to the conclusions made by Fourcaud et al. (2008), who pointed out the role of taproot and lateral root sizes on root-soil plate dimensions, and thus on root anchorage strength, although their simulations were carried out on over-simplified 2D structures. In addition, our study showed a non-negligible secondary effect of the basal diameter of the windward shallow roots on TMc. This supports the findings obtained from numerical tree-pulling experiments: windward shallow roots were stressed most when ward shallow roots, windward $L$ length of the windward shallow roots outside the ZRT, perpendicular 1 base diameter of the perpendicular shallow roots, perpendicular 2 intermediate diameter of the perpendicular shallow roots, perpendicular 3 distal diameter of the perpendicular shallow roots, perpendicular $L$ length of the perpendicular shallow roots outside the ZRT, windward ZRT sinker 1 base diameter of the windward sinker roots in the ZRT, windward ZRT sinker 2 distal diameter of the windward sinker roots in the ZRT, windward ZRT sinker $L$ length of the windward sinker roots in the ZRT, windward sinker diam diameter of the windward sinker roots outside the ZRT, windward sinker $L$ length of the windward sinker roots outside the ZRT

ultimate anchorage failure occurred. In addition, windward shallow roots were the second important root component contributing to TMc, after the taproot (Yang et al. 2017). This important role of windward shallow roots was also highlighted by field tree-pulling experiments of larger trees (Coutts 1983, 1986; Cucchi et al. 2004). However, the quantitative evaluation of specified root components is generally difficult and inapplicable in field tree-pulling experiments. Nevertheless, the importance of windward shallow roots 

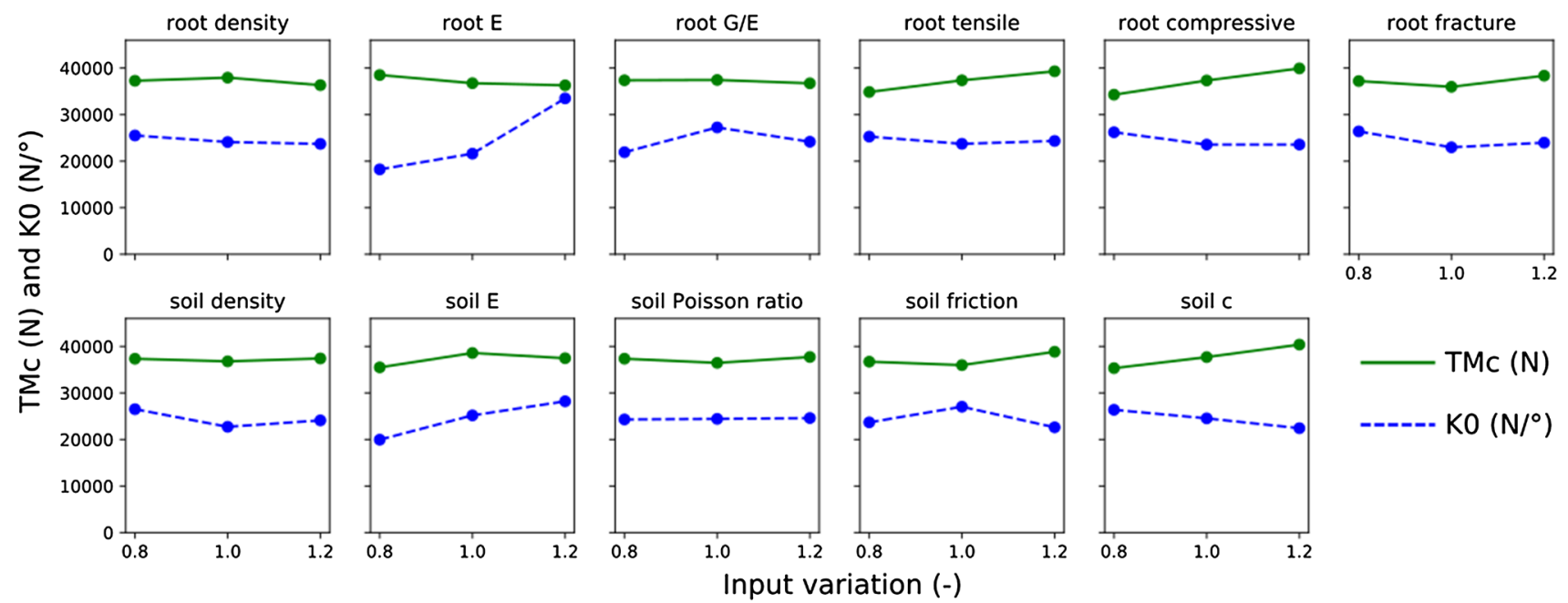

$\mathrm{KO}\left(\mathrm{N} /{ }^{\circ}\right)$

Fig. 3 Variation in anchorage strength TMc (unit in N.m; green solid lines) and anchorage rigidity (unit in $\mathrm{N} . \mathrm{m} /{ }^{\circ}$; blue-dashed lines) in response to $\pm 20 \%$ variations in root and soil material parameters. The 11 root and soil material parameters shown in the figure are: root density; root $E$ root elastic modulus, root $G / E$ ratio of root shear modulus

could be elucidated indirectly through comparisons between damaged and undamaged trees and observed root acclimation. First, in mature $P$. pinaster, uprooted trees had a smaller root volume of windward shallow roots beyond the ZRT and leeward roots in the ZRT than undamaged trees (Danjon et al. 2005). Second, windward edge $P$. pinaster trees usually present a larger windward sector to better resist winds (Cucchi et al. 2004). None of the material factors played a major role in TMc comparable to the key geometric factors.

Unlike the critical turning moment TMc, anchorage stiffness $\mathrm{K} 0$ is more sensitive to the geometric and material factors of roots and soil. Taproot depth, taproot basal and intermediate diameters and basal diameter of the leeward shallow roots are the geometric factors most responsible for anchorage stiffness. The elastic modulus of roots also plays a major role in $\mathrm{K} 0$. These findings support previous root architectural analyses. For instance, Danquechin Dorval et al. (2016) suggested that a large taproot, either short and thick or long and thin, is beneficial for the anchorage of young $P$. pinaster. The role of the basal area of leeward shallow roots has been illustrated in previous experimental studies and numerical tree-pulling simulations (Nicoll and Ray 1996; Crook and Ennos 1996; Harrington and DeBell 1996; Yang et al. 2017). The analysis showed that the base of leeward shallow roots is the most active part when the stem begins to bend. Root architectural analyses performed on young $P$. pinaster specimens suggested the importance of deep roots associated with the taproot. In 8-m high $P$. Pinaster trees, a large volume of deep root branching from the taproot improves anchorage by guying the end of the taproot (Danquechin Dorval et al. 2016). The role of deep and root elastic modulus, root tensile root tensile strength, root compressive root compressive strength, root fracture root fracture energy; soil density, soil E soil elastic modulus; soil Poisson's ratio, soil friction soil internal friction angle, soil $c$ soil cohesion

roots in mature $P$. pinaster is less clear. We did not test the deep roots in the present study because of highly variable size, orientation and branching patterns. The absence of deep roots explains that the deeper part of the taproot alone often broke at the beginning of the simulated overturning process (examples of simulations visualized in Yang et al. 2017). Overall, the key root architectural factors of $\mathrm{K} 0$ are located within an active zone closely surrounding the taproot, including the basal area of leeward shallow roots. This zone is much smaller than the root-soil plate that we found responsible for TMc. Physically, this makes sense. As K0 was defined at the very beginning of the overturning process, at this stage only the zone in the immediate vicinity of the stem base was stressed, whereas the TMc was defined at the anchorage failure which results from successive root failures and soil yielding within and surrounding the root-soil plate during the entire overturning process (Coutts 1983, 1986).

Our study treated tree anchorage from the mechanical perspective and we treated tree root systems as passive engineering structures. The Taguchi orthogonal arrays were chosen because the method was consistent with our assumption and our engineering approach to modeling tree anchorage (Finite Element Method). Consequently, only the main linear effects of factors were examined and any effects of a higher order including factor interactions were neglected. However, many roots and soil factors are closely related, and the problem of tree stability is nonlinear. Multiple factors may act together and induce possible additive or opposite effects on tree anchorage. On the biological level, the morphology of the root system itself provides strong evidence of the complex root-root and root-soil interactions. For 
instance, the maximum root depth may be directly related to the soil structure, fluctuations of the water table and the presence of hard pan. In our study, the parametrization was based on measurements. This not only summarized the main characteristics of young $P$. pinaster trees but also expressed the consequences of these interactions. Thus, the results should also be interpreted as integrated effects. Substantial knowledge is still needed to further explain the causality and the relations between roots and soil characteristics. Trees are biological structures that evolve as a function of species-dependent patterns. Moreover, trees acclimate responsively to external stimuli. This biological nature of trees and the dynamic processes occurring during their lifespan lead to impressive variability in root system architecture, the mechanical properties of root tissues and also has an impact on the soil environment (Telewski and Jaff 1986; Di Iorio et al. 2005; Coutand et al. 2008; Bonnesoeur et al. 2016). In addition, seasonal changes, site conditions, silvicultural practices, etc. also imply significant variability in soil material properties (Horn and Fleige 2003; Défossez et al. 2003; Horn et al. 2007; Saffih-Hdadi et al. 2009). So far, little knowledge is available to quantify this variability, thus more extensive sensitivity analysis is advisable. Our current study presented limitations in terms of quantitative interpretations, but could serve as the first step of qualitative factor screening for roots and soil in further investigations. Our results should be indicative for a number of Pinus species found in Europe with the same pattern of root system architecture (Köstler et al. 1968). This generic qualitative methodology for prioritizing key factors of tree stability is ready to be applied to other different plant species with diverse soil conditions. Nevertheless, it is necessary to adapt the biomechanical model to account for variability resulting from the species, tree age, specific season and site conditions, etc. For instance, the anchorage of a mature P. pinaster can be simplified to an entire root-soil plate within which the soil and roots compress into a compact block (Danjon et al. 2005). In such cases, root morphological traits are merged with soil in the block, and the soil material will no longer be characterized by the same mechanical laws as in the current model. Therefore, the important role played by root morphological traits for young trees could shift to the entire soil block when trees grow older.

With a small number of numerical experiments, the Taguchi orthogonal arrays made it possible to consider numerous input parameters and highlight the most important features of the root-soil system. The key factors found separately for TMc and $\mathrm{K} 0$ summarize the findings from previous disparate studies well (Coutts 1983, 1986; Peltola et al. 1999; Cucchi et al. 2004; Danjon et al. 2005; Danquechin Dorval et al. 2016; Yang et al. 2017). Overall, root morphology was found to have a greater influence on the entire tree overturning process than the material properties of roots and soil.
This result on tree anchorage reflects the same tendency as swaying tree aerial parts (Sellier and Fourcaud 2009). These results also highlight the key variables that could be used to develop a parsimonious relationship for tree anchorage that can be used as an input in future wind risk models.

Author contribution statement Conceived the idea and designed the sensitivity analysis: MY, PD, FD, TF. Performed the simulations: MY. Analyzed data: MY and PD. Wrote the manuscript: MY, PD, FD.

Acknowledgements This work was funded by the Aquitaine Region with the FAST-A project, and by the French National Research Agency (ANR) with the TWIST (ANR-13-JS06-0006) and FOR-WIND (ANR12-AGRO-0007) projects. It was also carried out in the framework of the Cluster of Excellence COTE (ANR-10-LABX-45). We thank Dr. Mark Irvine for his technical aid for the ABAQUS computations. AMAP (Botany and Computational Plant Architecture) is a joint research unit which associates CIRAD (UMR51), CNRS (UMR5120), INRA (UMR931), IRD (2M123), and Montpellier 2 University (UM27); http://amap.cirad.fr/.

\section{Compliance with ethical standards}

Conflict of interest The authors declare that they have no conflict of interest.

\section{References}

Achim A, Nicoll BC (2009) Modelling the anchorage of shallow-rooted trees. Forestry 82:273-284. https://doi.org/10.1093/forestry/cpp00 4

Augusto L, Achat DL, Bakker MR et al (2015) Biomass and nutrients in tree root systems-sustainable harvesting of an intensively managed Pinus pinaster (Ait.) planted forest. GCB Bioenergy 7:231-243. https://doi.org/10.1111/gcbb.12127

Autrique L, Lormel C (2008) Numerical design of experiment for sensitivity analysis - application to skin burn injury prediction. IEEE Trans Biomed Eng 55(4):1279-1290

Bonnesoeur V, Constant T, Moulia B, Fournier M (2016) Forest trees filter chronic wind-signals to acclimate to high winds. New Phytol. https://doi.org/10.1111/nph.13836

Coutand C, Dupraz C, Jaouen G et al (2008) Mechanical stimuli regulate the allocation of biomass in trees: demonstration with young Prunus avium trees. Ann Bot 101:1421-1432

Coutts MP (1983) Root architecture and tree stability. Plant Soil 71:171-188. https://doi.org/10.1007/BF02182653

Coutts MP (1986) Components of tree stability in sitka spruce on peaty gley soil. Forestry 59:173-197

Coutts MP, Nielsen CCN, Nicoll BC (1999) The development of symmetry, rigidity and anchorage in the structural root system of conifers. Plant Soil 217:1-15

Crook MJ, Ennos AR (1996) The anchorage mechanics of deep rooted larch, Larix europea $\times$ L. japonica. J Exp Bot 47(10):1509-1517

Crook MJ, Ennos AR, Banks JR (1997) The function of buttress roots: a comparative study of the anchorage systems of buttressed (Aglaia and Nephelium ramboutan species) and non-buttressed (Mallotus wrayi) tropical trees. J Exp Bot 48:1703-1716 
Cucchi V, Meredieu C, Stokes A et al (2004) Root anchorage of inner and edge trees in stands of Maritime pine (Pinus pinaster Ait.) growing in different podzolic soil conditions. Trees 18:460-466. https://doi. org/10.1007/s00468-004-0330-2

Danjon F, Fourcaud T, Bert D (2005) Root architecture and wind firmness of mature Pinus pinaster. New Phytol 168:387-400

Danjon F, Caplan JS, Fortin M, Meredieu C (2013) Descendant root volume varies as a function of root type: estimation of root biomass lost during uprooting in Pinus pinaster. Front Plant Sci 4:402

Danquechin Dorval A, Meredieu C, Danjon F (2016) Anchorage failure of young trees in sandy soils is prevented by a rigid central part of the root system with various designs. Ann Bot 118:747-762

Dar FH, Meakin JR, Aspden RM (2002) Statistical methods in finite element analysis. J Biomech 35:1155-1161

Défossez P, Richard G, Boizard H, O’Sullivan MF (2003) Modeling change in soil compaction due to agricultural traffic as function of soil water content. Geoderma 116:89-105

Di Iorio A, Lasserre B, Scippa GS, Chiatante D (2005) Root system architecture of Quercus pubescens trees growing on different sloping conditions. Ann Bot 95:351-361

Dupont S (2016) A simple wind-tree interaction model predicting the probability of wind damage at stand level. Agric For Meteorol 224:49-63

Dupont S, Ikonen VP, Väisänen H, Peltola H (2015a) Predicting tree damage in fragmented landscapes using a wind risk model coupled with an airflow model. Can J For Res 45:1065-1076

Dupont S, Pivato D, Brunet Y (2015b) Wind damage propagation in forests. Agric For Meteorol 214:243-251

Dupuy L, Fourcaud T, Stokes A (2005) A numerical investigation into the influence of soil type and root architecture on tree anchorage. Plant Soil 278:119-134

Dupuy L, Fourcaud T, Lac P, Stokes A (2007) A generic 3D finite element model of tree anchorage integrating soil mechanics and real root system architecture. Am J Bot 94:1506-1514

Ennos AR (2000) The mechanics of root anchorage. Adv Bot Res 33:133-157

Fourcaud T, Ji JN, Zhang ZQ, Stokes A (2008) Understanding the impact of root morphology on overturning mechanisms: a modelling approach. Ann Bot 101:1267-1280. https://doi.org/10.1093/ $\mathrm{aob} / \mathrm{mcm} 245$

Fraser AI, Gardiner B (1967) Rooting and stability in Sitka spruce. HM Stationery Office, London

Gardiner B, Blennow K, Carnus J-M, Fleischer P (2010) Destructive storms in European forests: past and forthcoming impacts. European Forest Institute, Finland

Gardiner B, Peltola H, Kellomäki S (2000) Comparison of two models for predicting the critical wind speeds required to damage coniferous trees. Ecol Model 129:1-23

Ghani MA, Stokes A, Fourcaud T (2009) The effect of root architecture and root loss through trenching on the anchorage of tropical urban trees (Eugenia grandis Wight). Trees 23:197-209. https://doi. org/10.1007/s00468-008-0269-9

Hale SE, Gardiner B, Peace A, Nicoll B, Taylor P, Pizzirani S (2015) Comparison and validation of three versions of a forest wind risk model. Environ Model Softw 68:27-41

Harrington CA, DeBell D (1996) Above- and below-ground characteristics associated with wind toppling in a young Populus plantation. Trees 11:109-118. https://doi.org/10.1007/PL00009655

Horn R, Fleige H (2003) A method for assessing the impact of load on mechanical stability and on physical properties of soils. Soil Till Res 73:89-99

Horn R, Vossbrink J, Peth S, Becker S (2007) Impact of modern forest vehicles on soil physical properties. For Ecol Manag 248:56-63

James K, Hallam C, Spencer C (2013) Measuring tilt of tree structural root zones under static and wind loading. Agric For Meteorol 168:160-167
Jonsson MJ, Foetzki A, Kalberer M, Lundström T, Ammann W, Stöckli V (2006) Root-soil rotation stiffness of Norway spruce (Picea abies (L.) Karst) growing on subalpine forested slopes. Plant Soil 285:267-277

Köstler JN, Brückner E, Bibelriether H (1968) Die Wurzeln der Waldbäume. Paul Parey, Hamburg

Lin CL, Yu JH, Liu HL, Lin CH, Lin YS (2010) Evaluation of contributions of orthodontic mini-screw design factors based on FE analysis and the Taguchi method. J Biomech 43:2174-2181

Moore JR, Tombleson JD, Turner JA, van der Colff M (2008) Wind effects on juvenile trees: a review with special reference to toppling of radiata pine growing in New Zealand. Forestry 81:377-387. https ://doi.org/10.1093/forestry/cpn023

Neild SA, Wood CJ (1999) Estimating stem and root-anchorage flexibility in trees. Tree Physiol 19:141-151

Nicoll BC, Ray D (1996) Adaptive growth of tree root systems in response to wind action and site conditions. Tree Physiol 16:891-898

Nicoll BC, Gardiner B, Rayner B, Peace AJ (2006) Anchorage of coniferous trees in relation to species, soil type, and rooting depth. Can J For Res 36:1871-1883

Peltola H, Kellomaki S, Vaisanen H, Ikonen V-P (1999) A mechanistic model for assessing the risk of wind and snow damage to single trees and stands of Scots pine, Norway spruce, and birch. Rev Can Rech For 29:647-661

Pivato D, Dupont S, Brunet Y (2014) A simple tree swaying model for forest motion in windstorm conditions. Trees Struct Funct 28:281-293

Rodriguez M, De Langre E, Moulia B (2008) A scaling law for the effects of architecture and allometry on tree vibration modes suggests a biological tuning to modal compartmentalization. Am J Bot 95:1523-1537

Saffih-Hdadi K, Défossez P, Richard G et al (2009) A method for predicting soil susceptibility to the compaction of surface layers as a function of water content and bulk density. Soil Tillage Res 105:96-103

Sellier D, Fourcaud T (2009) Crown structure and wood properties: influence on tree sway and response to high winds. Am J Bot 96:885-896

Sellier D, Brunet Y, Fourcaud T (2008) A numerical model of tree aerodynamic response to a turbulent airflow. Forestry 81:279-297

Shabani F, Kumar L (2014) Sensitivity analysis of CLIMEX parameters in modeling potential distribution of Phoenix dactylifera L. PloS one 9(4):e94867

Stokes A (1999) Strain distribution during anchorage failure of Pinus pinaster Ait. at different ages and tree growth response to windinduced root movement. Plant Soil 217:17-27

Taguchi G (1987) System of experimental design: engineering methods to optimize quality and minimize costs. UNIPUB/Kraus International Publications, New York

Telewski FW, Jaffe MJ (1986) Thigmomorphogenesis: field and laboratory studies of Abies fraseri in response to wind or mechanical perturbations. Physiol Plant 66:211-218

Yang M (2014) Ancrage racinaire des arbres: modélisation et analyses numériques des facteurs clés de la résistance au vent du Pinus pinaster (Doctoral dissertation, University of Bordeaux)

Yang M, Défossez P, Danjon F, Fourcaud T (2014) Tree stability under wind: simulating uprooting with root breakage using a finite element method. Ann Bot 114:695-709. https://doi.org/10.1093/aob/mcu122

Yang M, Défossez P, Danjon F, Dupont S, Fourcaud T (2017) Which root architectural elements contribute the best to anchorage of Pinus species? Insights from in silico experiments. Plant Soil. https://doi. org/10.1007/s11104-016-2992-0 